\title{
Toxicity and biodegradability of caffeic acid in anaerobic digesting sludge
}

\author{
JE Hernandez ${ }^{1,2 *}$ and RGJ Edyvean ${ }^{3}$ \\ 'Chemical and Environmental Engineering Department, Bioinspired Engineering Research Group, University of Nottingham, Malaysia, \\ Jalan Broga, Semenyih, Selangor, 43500, Malaysia \\ ${ }^{2}$ Chemical and Environmental Engineering Department, University of Nottingham, United Kingdom \\ ${ }^{3}$ Department of Chemical and Process Engineering, University of Sheffield, Kroto Institute, North Campus Broad Lane, \\ Sheffield, $\mathrm{S} 3 \mathrm{7HQ}$, United Kingdom
}

\begin{abstract}
Caffeic acid in waste comes from a variety of industries, and its disposal is likely to increase due to emerging processes such as graphene production and use in healthcare products. The current sustainable option to treat waste caffeic acid and prevent its natural transformation in soil to greenhouse gases, is anaerobic digestion. However, little is known about the toxic and inhibitory effects of caffeic acid on biogas production as well as its ultimate anaerobic biodegradability; or about the reactiveadsorptive processes taking place with caffeic acid in sludge, metabolic intermediates, thermodynamic limitations and the effects on extracellular polymeric substances (EPS). Standard methods revealed that $80 \%$ of biogas production $\left(\mathrm{EC}_{80}\right)$ from a readily digestible biomass was inhibited at $389 \mathrm{mg}$ caffeic acid. $\mathrm{g}^{-1}$ VSS. Up to $52 \%$ of caffeic acid was biodegraded. $\beta$-oxidation and reductive dehydroxylation were the initial activation reactions transforming caffeic acid into typical polyphenol structural units (protocatechuic acid and 4HBA). Adsorption of caffeic acid (53.3\% and 28.6\%) to the sludge occurred even at inhibitory concentrations. The EPS structure remained unchanged regardless of the increase in concentration of caffeic acid. Reasonable concentrations of caffeic acid could be co-digested with a similar readily digestible biomass with an expected reduction in biogas production. It is feasible to treat waste caffeic acid by anaerobic digestion and adsorption of its derivates, in order to reduce the contribution to global warming and to protect the environment.
\end{abstract}

Keywords: anaerobes, anaerobic digestion, biogas, biomass, caffeic acid, graphene, inhibition, polyphenols, renewable energy, toxicity, wastewater

\section{INTRODUCTION}

Caffeic acid is an antioxidant phenolic naturally found in coffee, fruits, vegetables, seasonings and many other agricultural products (Stojković et al., 2013). Recently, caffeic acid has gained attention for its application in the recovery of metals (Craioveanu et al., 2014), the production of graphene (Bo et al., 2014) and antimicrobial nanogels (Zhaveh et al., 2015) as well as in cancer research for its anti-inflammatory; anti-mutagenic and anti-tumoural activity (VanBesien and Marques, 2003). This trend suggests an increase in caffeic acid use and disposal, consequently adding to that already discharged by the coffee, olive oil, red wine and pharmaceutical industries (Michailof et al., 2008).

In the Mediterranean basin alone, approximately $1056 \mathrm{t}$ of caffeic acid are released annually from countries discharging olive oil mill wastewater (calculated from Beccari et al., 1996; D'Annibale et al., 2000). To achieve sustainable development goals, one of the best ways to treat this wastewater would be by anaerobic digestion due to its well-recognised sustainability. However, the effect that caffeic acid may have in the digesting sludge and ultimately on biogas production remains unclear.

Previous experiments with caffeic acid and digesting sludge were unsuccessful (Borja et al., 1996). With pure cultures, however, the conversion of caffeic acid to methane is likely to occur, as revealed by studies on the methanogenesis of caffeic acid by ferulic acid-degrading anaerobic bacteria (Evans and Fuchs, 1988).

\footnotetext{
* To whom all correspondence should be addressed.

e-mail:info@ernestohernandez.org
}

Received 2 June 2017, accepted in revised form 1 December 2017.
So far, there is not a clear understanding of the phenomena occurring when caffeic acid is present in digesting sludge, where simultaneous transport and reaction are likely to occur. It is known that under some anaerobic conditions caffeic acid may lead to products acting differently in terms of toxicity or digestibility. For instance, in aqueous systems with traces of oxygen (nearly anaerobic), caffeic acid undergoes autoxidation (Field and Lettinga, 1989) resulting in the creation of aggregates with adsorptive properties (Rochelle, 2001). In fermentative conditions, caffeic acid is transformed to hydrocaffeate; thus acetate yield decreases, as does methane production (Heider and Fuchs, 1997b). In the human colonic microflora, caffeic acid is converted to more biodegradable molecules, such as benzoic acid (Olthof et al., 2003).

This research aimed to assess the toxicity and biodegradability of caffeic acid by methanogenic anaerobic digestion with standardized methods. In addition, it gives preliminary insight into the formation of aggregates due to adsorption, the formation of initial activation metabolites, and thermodynamic aspects and morphology of the anaerobic digesting sludge.

\section{MATERIALS AND METHODS}

\section{Toxicity assessment}

This assessment consisted of an evaluation of the toxic effects of caffeic acid (CAF) on biogas production from a readily digestible material, following the standard ISO 13641 (2003). Actively digesting sludge was collected from the Aldwarke wastewater treatment plant, Rotherham, UK. Gas-tight 
plastic expandable bottles were used for sludge collection and transportation was done in insulated containers $\left(35 \pm 1^{\circ} \mathrm{C}\right)$. The sludge was sieved $\left(1 \mathrm{~mm}^{2}\right)$ to remove sand and other particles before it was tested. To make sure caffeic acid remained toxic and nondegradable during the experiment, the sludge was not acclimatised to caffeic acid.

The substrate used was a mixture of $10 \mathrm{~g}$ of nutrient broth, $10 \mathrm{~g}$ of yeast extract and $10 \mathrm{~g}$ of $\mathrm{D}$-glucose dissolved in $100 \mathrm{~mL}$ of de-aerated and de-ionized water. This mixture was sterilized using a $0.2 \mu \mathrm{m}$ Millipore glass microfibre membrane. In this assay, the substrate is not a limiting factor and losses of its components as vapours are unlikely to occur due to their high vapour pressure. 3,5-dichlorophenol was used as a reference substance (RS) at a concentration of $150 \mathrm{mg} \cdot \mathrm{L}^{-1}$. All chemicals were obtained from Sigma Aldrich, Co. (UK), and all the protocols were carried out anaerobically under sterile conditions (containment level 2).

Preliminary tests were carried out to determine a suitable range of concentrations of both caffeic acid (CAS 331-39-5) and inoculum. The initial biomass concentration was evaluated in terms of total solids (TS $=27.2 \mathrm{~g} \cdot \mathrm{L}^{-1}, \sigma=4.9 \%$ ), total suspended solids (TSS $\left.=26.9 \mathrm{~g} \cdot \mathrm{L}^{-1}, \sigma=8.7 \%\right)$ and volatile suspended solids (VSS $=17.6 \mathrm{~g} \cdot \mathrm{L}^{-1}, \sigma=8.1 \%$ ) by applying the drying and ignition methods according to APHA (1998).

The bioreactors were serum bottles $(155 \mathrm{~mL})$ prepared inside an anaerobic chamber full of nitrogen (99\%). Three sets of triplicate bottles were loaded with sludge and substrate in the following fashion: with and without the addition of either caffeic acid (controls: CTRL and tests: TX) or 3,5-dichlorophenol (RS). The bottles were then crimped with aluminium caps and butyl rubber septa, thus creating airtight bioreactors containing 100 $\mathrm{mL}$ of liquid and $55 \mathrm{~mL}$ of gas headspace. Then, the bioreactors were simultaneously incubated for 3 days at $35 \pm 1^{\circ} \mathrm{C}$ and inverted manually twice a day, every day.

Initially, the concentrations of caffeic acid in TX were 500, $1000,2000,4000$ and $8000 \mathrm{mg} \cdot \mathrm{L}^{-1} \mathrm{CAF}$. The pressure in the headspace was measured and recorded every $24 \mathrm{~h}$ with a digital pressure meter fitted with a three-way stopcock. Any errors introduced by the volume of the tubing connecting the bottle and pressure meter were negligible (less than $0.5 \pm 0.05 \mathrm{~mL}$ ). At the end of each reading, the headspace pressure was equalized to the atmospheric pressure by releasing the biogas via the three-way stopcock.

The cumulative pressure of individual bioreactors was calculated from daily readings and plotted against time. Then, the toxicity of caffeic acid at $48 \mathrm{~h}$ duration was reported in terms of effective concentration $\left(\mathrm{EC}_{\mathrm{I}}\right.$ ) that generated $20 \%, 50 \%$ and $80 \%$ inhibition while considering the controls. In addition, a fitting polynomial expression of per cent of inhibition (\%I) as a function of Log C, for each TX triplicate was created and the averaged polynomic was reported to allow for calculations of $\mathrm{EC}_{\mathrm{I}}$ as a function of \%I.

\section{Anaerobic biodegradability experiment}

\section{Experimental setup}

This study was conducted following the standard ISO 11734 (1999). The medium was prepared with the materials reported in Table 1. Oxygen was removed from the medium by bubbling $99 \%$ nitrogen for 20 min per litre immediately before use, and its presence was indicated by the pink colour given by the redox indicator resazurin. This was followed by the addition of sodium sulphide nonahydrate to ensure sufficient reductive capacity in the experiment. Caffeic acid (CAF) and phenol were used as test and reference substrates respectively. Caffeic acid was added as a solid owing to its low solubility in water and its ability to be dissolved in the final aqueous reaction volume.

The inoculum was prepared as shown in the toxicity experiment (above) but also pre-digested without the addition of nutrients or substrate, anaerobically at $35 \pm 0.5^{\circ} \mathrm{C}$ for 7 days to reduce background gas production and, therefore, decrease the effects of the blanks. The amount of inorganic carbon (IC) in the sludge was eliminated by washing it with medium and centrifuging at $3000 \mathrm{~g}$ for $5 \mathrm{~min}$. Then, the pellet was finally suspended in fresh medium.

Preliminary experiments were carried out to determine a range of concentrations of caffeic acid to work with, and were expressed in terms of carbon to facilitate carbon mass balance (CD). Such concentrations were 100, 200, 400, 800 and $1600 \mathrm{mg} \cdot \mathrm{L}^{-1}$ carbon. In the case of the inoculum, a biomass amount of $1.3 \mathrm{~g} \cdot \mathrm{L}^{-1} \mathrm{VSS}, \sigma=3 \%$ represented its concentration in the final reaction volume.

The filling of serum bottles was carried out inside an anaerobic chamber full of nitrogen. Sets of triplicates were prepared for the blank (BLK), control (CTRL), reference (RS) and test $(\mathrm{CD})$. An extra triplicate was prepared to measure the $\mathrm{pH}$ at the beginning and at the end of the experiment. All the bottles were incubated at $35^{\circ} \mathrm{C}$ for 250 days. Pressure was measured as indicated in the toxicity test.

\section{Data analysis}

This was carried out by following the procedure described in ISO 11734 (1999). The net production of $\mathrm{CH}_{4}$ and $\mathrm{CO}_{2}$ was calculated by subtracting the effects of the blanks. Total $\mathrm{CH}_{4}$ and $\mathrm{CO}_{2}$ were calculated by adding their liquid and headspace fractions. In the liquid, the amount of $\mathrm{CH}_{4}$ and $\mathrm{CO}_{2}$ was calculated by applying Henry's law and the constants reported for Anaerobic Digestion Model No. 1 (ADM1) (Batstone et al., 2002). In the headspace, the calculation was done by applying the ideal gas equation $(\mathrm{PV}=\mathrm{nRT})$ since pressure and temperature were close to standard conditions in daily readings.

\section{Intramolecular interactions (adsorption-aggregation)}

Adsorption and chemical transformations were measured in a separate triplicate of bottles (AD) containing 100, 800 and $1600 \mathrm{mg} \cdot \mathrm{L}^{-1}$ carbon from caffeic acid and inoculum as described above. These concentrations were selected from a preliminary test showing the extent of caffeic acid biodegradability and inhibition of biogas production.

When the exponential phase of cumulative gas production was reached, the samples were taken out. Then, filtered (F) and unfiltered (U) fractions were stored at $4^{\circ} \mathrm{C}$ and $0^{\circ} \mathrm{C}$, respectively (i.e. $\mathrm{F}(0,4)$ and $\mathrm{U}(0,4))$. Samples were also taken from bottles containing the highest inhibitory concentrations (C800 and C1600). Caffeic acid was extracted from the sludge by the traditional evaporation-condensation method (APHA, 1998), relying on the addition of diluted $\mathrm{H}_{3} \mathrm{PO}_{4}$ and glass beads to reduce the sample boiling point. Less than $90 \%$ of the sample was recoverable as condensate and thus this led to a systematic error in caffeic acid recovery. The condensate was then filtered and adjusted to an acceptable $\mathrm{pH}$ for subsequent liquid chromatography analysis (HPLC). Losses of caffeic acid were due to the creation of a black crust during the boiling process used to digest the sludge with acid. 
TABLE 1

Physicochemical properties of caffeic acid and chemical composition of the culture medium utilized in the inhibition experiments

\begin{tabular}{|l|c|l|l|l|c|}
\hline Physicochemical properties & & Reagents (medium) & $\mathbf{g} \cdot \mathrm{L}^{-1}$ & $\begin{array}{l}\text { Reagents (trace } \\
\text { elements }\end{array}$ & $\mathbf{g} \cdot \mathrm{L}^{-1}$ \\
\hline Molecular weight $\left(\mathrm{g} \cdot \mathrm{moL}^{-1}\right)$ & 180.06 & $\mathrm{KH}_{2} \mathrm{PO}_{4}$ & 0.27 & $\mathrm{MnCl}_{2} \cdot 4 \mathrm{H}_{2} \mathrm{O}$ & 0.05 \\
\hline Melting point $\left({ }^{\circ} \mathrm{C}\right)$ & 218 & $\mathrm{NaHPO}_{4} \cdot 12 \mathrm{H}_{2} \mathrm{O}$ & 1.12 & $\mathrm{H}_{3} \mathrm{BO}_{3}$ & 0.005 \\
\hline Boiling point $\left({ }^{\circ} \mathrm{C}\right)$ & $416.8 \pm 35.0$ & $\mathrm{NH}_{4} \mathrm{Cl}$ & 0.53 & $\mathrm{ZnCl}_{2}$ & 0.005 \\
\hline Size $(\AA)$ & $5.79 \times 10.67$ & $\mathrm{CaCl}_{2} \cdot 2 \mathrm{H}_{2} \mathrm{O}$ & 0.075 & $\mathrm{CuCl}_{2}$ & 0.003 \\
\hline Solubility & $50 \mathrm{mg} \cdot \mathrm{L}^{-1}$ in ethanol & $\mathrm{MgCl}_{2} \cdot 6 \mathrm{H}_{2} \mathrm{O}$ & 0.1 & $\mathrm{Na}_{2} \mathrm{MoO}_{4} \cdot 2 \mathrm{H}_{2} \mathrm{O}$ & 0.001 \\
\hline Polarity $(\log \mathrm{P})$ & $1.424 \pm 0.360$ & $\mathrm{FeCl}_{2} \cdot 4 \mathrm{H}_{2} \mathrm{O}$ & 0.02 & $\mathrm{CoCl}_{2} \cdot 6 \mathrm{H}_{2} \mathrm{O}$ & 0.1 \\
\hline \multirow{2}{*}{} & & $\mathrm{C}_{12} \mathrm{H}_{6} \mathrm{NNaO}_{4}$ & 0.001 & $\mathrm{NiCl}_{2} \cdot 6 \mathrm{H}_{2} \mathrm{O}$ & 0.01 \\
\cline { 2 - 6 } & & $\mathrm{N}_{2} \mathrm{~S} \cdot 9 \mathrm{H}_{2} \mathrm{O}$ & 0.1 & $\mathrm{Na}_{2} \mathrm{SeO}_{3}$ & 0.005 \\
\hline
\end{tabular}

${ }^{a}$ Data obtained from Science Finder Scholar database (2002) and the supplier Sigma-Aldrich (2004).

${ }^{b}$ Longitudinal and transversal longest distances of molecule were determined in the software ACD ChemSketch 8.17.

${ }^{c}$ Very soluble after pH 7; $50 \mathrm{mg} \cdot \mathrm{L}^{-1}$ in ethanol with heat; soluble in hot water and cold ethanol; alkaline solutions turn from yellow to orange.

\section{Chromatography and inorganic carbon analysis}

Caffeic acid and phenolic metabolites were analysed by high performance liquid chromatography (HPLC) (Perkin-Elmer, Co. (USA)) as previously described (Hernandez, 2007). Caffeic acid was used as standard. Interferences, e.g., phenol-decomposing anaerobes, EPS and inorganic particles, were eliminated by filtering samples through $0.45 \mu \mathrm{m}$ micro-filters. IC was analysed by total inorganic and organic carbon (TIC/TOC, Shimadzu, Co.) as previously described (Hernandez, 2007).

Methane and carbon dioxide were analysed in a gas chromatograph (GC, Varian 3400) as previously described (Hernandez, 2007).

\section{Microscopic structure of sludge (scanning electron microscopy)}

The aim was to observe the structure of the microbial aggregate by giving insight into the space relationship between anaerobes, EPS (extracellular polymeric-like substances) and other materials. A sample was taken during the exponential phase of degradation and was examined under the scanning electron microscope (SEM) as previously described (Hernandez, 2007).

\section{RESULTS AND DISCUSSION}

\section{Toxicity}

CAF, as with many other phenolic compounds, has been considered to be a toxic agent of anaerobic wastewater treatment. This was thought to be due to its lack of conversion into methane when it was used as the only carbon source with anaerobic digesting sludge (Borja et al., 1996). However, this claim was probably a result of deploying an assay of short duration preventing the acclimation of microbes to caffeic acid which is a less biodegradable substrate.

In the present work, the biogas production (from a readily digestible medium) in all test bottles was inferior to that developed in the controls (CTRL), indicating that all of the caffeic acid concentrations were toxic (Fig. 1-A). At lower concentrations, there was an unexpected toxicity behaviour; i.e., when $\log \mathrm{C}$ and \% I described a curve (Fig. 1-B), the same
\%I corresponds to two different caffeic acid concentrations. However, at concentrations higher than $2000 \mathrm{mg}$. $\mathrm{L}^{-1} \mathrm{CAF}$, there was a direct relationship between dose and response and thus unique percentages of inhibition (\%I). A maximum of $88.7 \%(\sigma=1.5 \%)$ inhibition was observed at $8000 \mathrm{mg} \cdot \mathrm{L}^{-1} \mathrm{CAF}$. The ' $J$ ' shape of this plot indicates that the data did not follow a typical dose-response curve. These results show that caffeic acid would not represent a threat in co-digestion with another readily digestible biomass since the existing concentration in wastewater (35.2 $\mathrm{mg} \cdot \mathrm{L}^{-1}$ (D’Annibale et al., 2000)) is far from reaching the $\mathrm{EC}_{50}\left(206.1 \mathrm{mg} \cdot \mathrm{g}^{-1} \mathrm{VSS}\right)$ reported herein. The concentrations that promoted $20 \%, 50 \%$ and $80 \%$ inhibition in terms of actual biomass concentration $\left(\mathrm{EC}_{20}, \mathrm{EC}_{50}\right.$ and $\mathrm{EC}_{80}$ ) are shown in Table 2. The $r^{2}$ for the second-order fitting polynomials obtained for each triplicate bottle were 0.992 , 0.991 and 0.997 .

So far, the exact mechanism of toxicity of phenols and phenolic acids in anaerobic treatment systems remains unknown. Sierra-Alvarez (1991), for example, stated that the data required for clear answers are still lacking. But Sikkema et al. (1995) suggest that the cause is due to fragmented information in different scientific fields. We suggest that the chemistry is not the only factor to be considered when experimenting with phenolic compounds and digesting sludge under the conditions of the present experiments. Certainly, simultaneous reaction and transport phenomena are likely to happen. This can include: transport due to mass and energy gradients across the cells or extracellular polymericlike substances (EPS), and caffeic acid self-aggregation or adsorption to the sludge matrix, to cite a few examples. This assumption will be clarified in the following subsections.

It seems that toxic effects on the cellular membrane are less prone to occur, given the poor solubility of caffeic acid in water at $35^{\circ} \mathrm{C}$, which implies a low bioavailability for cell uptake. Therefore, the toxicity mechanism cannot be explained from the point of view of cell membrane inactivation due to interaction of its embedded lipids and proteins with toxic lipophilic compounds. On the other hand, the fraction of solubilised caffeic acid molecules may act differently. Caffeic acid is a weak acid with a hydrophobic side chain that in its protonated form can easily pass across the membrane to be dissociated in the 
cytoplasm, resulting in a reduction of the delta $\mathrm{pH}$ and leading to a decrease in the energy status of the cell. This was confirmed by the drop in $\mathrm{pH}$ at the end of the toxicity experiment in serum bottles, run in parallel, with and without caffeic acid (DU in Table 2).
Although the principles underpinning the toxicity behaviour of a phenolic in digesting sludge are still far from being explained, the present study delivers a practical answer to predict caffeic acid toxic effects $\left(\mathrm{EC}_{\% \mathrm{I}}\right)$, at a range of concentrations, to avoid perturbations in an anaerobic
A)

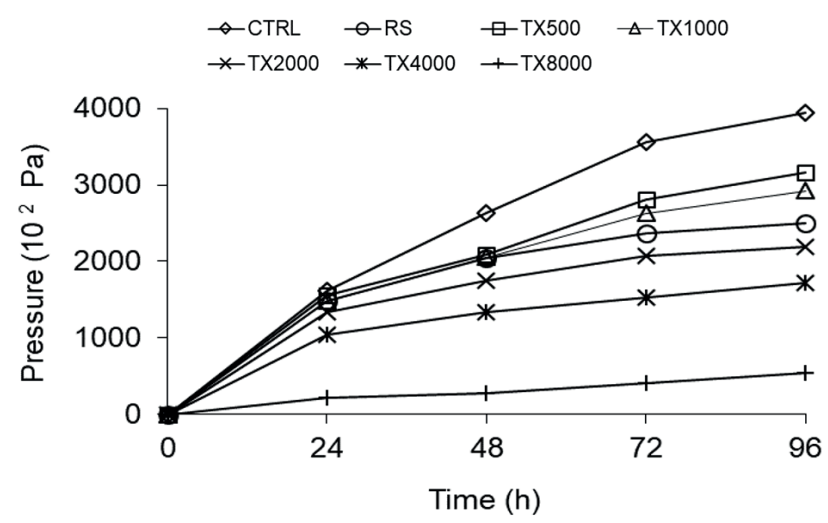

B)

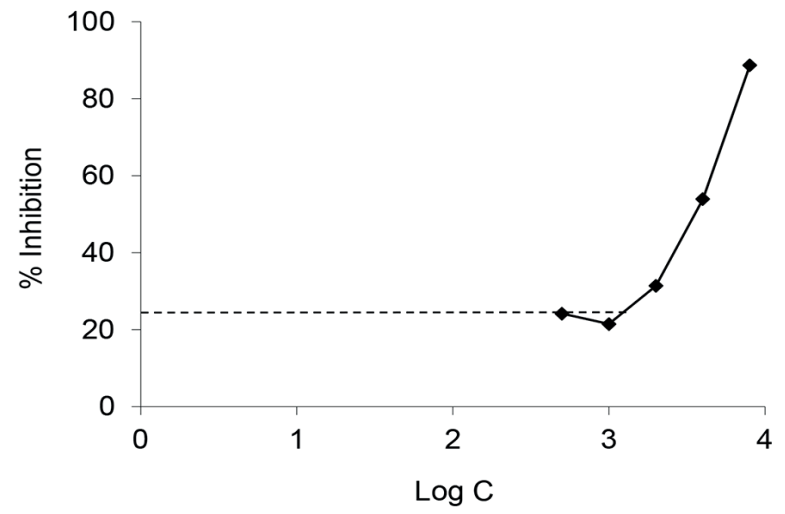

Figure 1

Toxicity of caffeic acid upon biogas production from a readily digestible material. (A) Cumulative pressure versus concentration and time. Blank $(B L K)$, reference substance ( $R S=150 \mathrm{mg} \cdot L^{-1} 3,5$-dichlorophenol) and test bottles (TX in mg. $L^{-1} C A F$ ) as indicated by ISO 13641 (2003). (B) Per cent of inhibition versus concentration (logarithmic) showing that in a region, two concentrations display the same extent of inhibition (dotted line). A good fit polynomial $\left(R^{2}=0.998\right)$ for the average triplicate of bottles is $\%=69.028(\log C)^{2}-402.05(\log C)+606.45$. The error bars were not included for the sake of clarity and because such values had a standard deviation of less than $3 \%$.

TABLE 2

Anaerobic toxicity and ultimate anaerobic biodegradability of caffeic acid. These tests are independent of each other.

\begin{tabular}{|c|c|c|c|c|c|c|c|c|c|}
\hline \multicolumn{3}{|l|}{ Toxicity } & \multicolumn{7}{|c|}{ Biodegradability } \\
\hline $\mathrm{V}_{1}(\mathrm{~L})^{\mathrm{a}}$ & \multicolumn{2}{|l|}{0.1} & \multirow{2}{*}{\multicolumn{2}{|c|}{ Concentration $\left(\mathrm{mg} \cdot \mathrm{L}^{-1} \mathrm{C}\right)$}} & \multirow{2}{*}{100} & \multirow{2}{*}{200} & \multirow{2}{*}{400} & \multirow{2}{*}{800} & \multirow{2}{*}{1600} \\
\hline$V_{g}(L)^{b}$ & 0.055 & & & & & & & & \\
\hline \multirow{3}{*}{\multicolumn{3}{|c|}{$E C_{1}\left(m g \cdot g^{-1} V S S\right)^{c}$}} & \multirow{2}{*}{$\Delta \mathrm{P}_{\max }$} & mbar & 582 & 1246 & 2444 & -453 & -399 \\
\hline & & & & $\% \sigma^{\mathrm{d}}$ & 3.9 & 15.8 & 14.29 & 3.57 & 1.85 \\
\hline & & & & $\mathrm{m}_{\mathrm{h}}(\mathrm{mg})$ & $4.2 \pm 1.7$ & $9.1 \pm 2.6$ & $17.7 \pm 3.8$ & $-3.3 \pm 0.2$ & $-2.9 \pm 0.2$ \\
\hline I (\%) & Mean & $\% \sigma^{d}$ & & $\mathrm{~m}_{1}(\mathrm{mg})$ & $3.0 \pm 0.2$ & $5.4 \pm 0.3$ & $6.5 \pm 0.1$ & $-2.9 \pm 0.4$ & $-3.0 \pm 0.1$ \\
\hline 20 & 48.4 & 9.7 & & $\mathrm{D}_{1}(\%)$ & $21.4 \pm 1.7$ & $19.5 \pm 0.1$ & $11.7 \pm 0.2$ & $-6.2 \pm 0.5$ & $-1.4 \pm 0.1$ \\
\hline 50 & 206.1 & 3.0 & & $\mathrm{D}_{\mathrm{h}}(\%)$ & $30.3 \pm 12.0$ & $32.4 \pm 9.1$ & $31.8 \pm 6.8$ & $-2.6 \pm 0.4$ & $-1.3 \pm 0.1$ \\
\hline 80 & 388.6 & 1.3 & & $\mathrm{D}_{\mathrm{t}}(\%)$ & $51.7 \pm 12.2$ & $51.9 \pm 9.2$ & $43.4 \pm 0.7$ & $-5.6 \pm 0.4$ & $-2.7 \pm 0.1$ \\
\hline \multicolumn{3}{|l|}{$\mathrm{pH}^{\mathrm{e}}$} & \multirow{2}{*}{ Mol fraction ${ }^{\mathrm{b}}$} & $\mathrm{CH}_{4}$ & 0.39 & 0.29 & 0.14 & -0.01 & ND \\
\hline & \multirow{2}{*}{ Start } & \multirow{2}{*}{ End } & & $\mathrm{CO}_{2}$ & 0.61 & 0.71 & 0.86 & 1.01 & 1.00 \\
\hline & & & \multicolumn{7}{|l|}{ Productivity } \\
\hline DU1 & 7.04 & 6.55 & \multicolumn{2}{|c|}{$\times 10^{-5} \mathrm{~mol} \mathrm{CH}_{4} \cdot \mathrm{VSS}^{-1} \cdot \mathrm{day}^{-1}$} & 5.79 & 2.86 & 1.61 & NEP & NEP \\
\hline DU2 & 6.17 & 5.73 & \multicolumn{2}{|c|}{$\times 10^{-5} \mathrm{~mol} \mathrm{CO}_{2} \cdot \mathrm{VSS}^{-1} \cdot \mathrm{day}^{-1}$} & 8.97 & 7.09 & 10.32 & NEP & NEP \\
\hline & & & \multicolumn{2}{|l|}{$\mathrm{pH}$ (end) } & 6.56 & 6.41 & 6.22 & 5.99 & 5.01 \\
\hline
\end{tabular}

a. Volume of liquor

b. Volume of headspace

c. This value represents the toxicity developed by the mass of caffeic acid over one gram of biomass (reported as VSS)

$d$. \% $\sigma$ is the per cent standard deviation between the set of triplicates

b. Molar fraction of the total amount of gas produced in both liquid and headspace

e. DU1 and DU2 contain sludge, substrate and water, but DU2 also contains $8000 \mathrm{mg} \cdot L^{-1}$ caffeic acid. The readings error was \pm 0.3 .

ND stands for not detectable

NEP means that no exponential phase in cells growth was achieved and this led to lack of methane 
digester. The experiments reported herein satisfied the validity criteria established in international standard ISO 13641-1 (2003), i.e., at the end of the test, the inhibition developed by the reference substance had to be higher than $20 \%$ and the pH in the controls had to range between 6.2 to 7.5. In the present experiment, such values were $23.1 \%(\sigma=8 \%)$ and $6.55 \pm 0.3$, respectively. The observed differences in $\mathrm{pH}$ may be due to the effect of using different sources of inoculum, as found by Moreno and Buitron (2004).

\section{Ultimate anaerobic biodegradability}

\section{Caffeic acid methanation and mineralization}

The experiments by Borja et al. (1996) led to the assumption that caffeic acid could not be converted to methane when it was used as the only carbon source. In the study, caffeic acid inhibited 65\% of the methane production associated with controls (without caffeic acid). We found that biogas formation from caffeic acid indeed took place under some experimental conditions.

From preliminary experiments (not reported here) the concentrations (CD) utilised in this biodegradation experiment were as follows: 100, 200, 400, 800 and $1600 \mathrm{mg} \cdot \mathrm{L}^{-1}$ carbon. The lag phase was directly proportional to the increment of concentration (17, 31 and 117 days) at 100, 200 and $400 \mathrm{mg} \cdot \mathrm{L}^{-1}$ carbon, respectively. Then, the plateau of biogas production was reached at 43, 82 and 217 days, and no significant changes were observed after 250 days in any replicate (Fig. 2). Higher concentrations (C800 and C1600) were completely inhibitory for biogas production (Fig. 3). Inhibition in this case may be due to simultaneous physicochemical and biochemical phenomena related to caffeic acid itself and its surroundings, as will be explained in the following subsections.

The mass balance of carbon from caffeic acid shows that a fraction of it was biologically converted to inorganic carbon (IC), which was dissolved in the liquid phase (21.4, 19.5 and $11.7 \%)$ and gasified into the headspace $\left(\mathrm{CH}_{4}\right.$ and $\left.\mathrm{CO}_{2}\right)$ at equilibrium. IC at C800 and C1600 was smaller $(<27$ and 30\%) than in the blanks, indicating an inhibitory effect upon the mineralization of background biomass. This ultimately led to a decrease in biomethanation $\left(\mathrm{D}_{\mathrm{h}}\right)$ and total biodegradation $\left(D_{t}\right)$, as shown in Table 2. Negative values confirm that both background IC and biogas were inhibited, and therefore this is a clear indication that ring fission and acetate production did not take place.

\section{Dose-response}

From C200 to C1600 there is a direct correlation between the dosage and inhibition of biogas produced (Fig. 1 B). A reduction of the mol fraction of methane was observed from C100 to C200. Inhibition is clearly evident at higher concentrations and the fundamental principles behind this atypical behaviour have not been explained as yet. Fedorak and Hudrey (1984) reported that acetogens are more sensitive than methanogens, contradicting the findings of Sorlini et al. (1986) (after Fiestas-Ros-de-Ursinos and Borja-Padilla, 1996), who suggested that caffeic acid inhibits acetogens and methanogens at concentrations higher than $0.25 \mathrm{~g} \cdot \mathrm{L}^{-1}$ and $0.12 \mathrm{~g} \cdot \mathrm{L}^{-1}$, respectively. Our results show that the $\mathrm{pH}$ changed inversely, when caffeic acid concentration increased, and was far (5.01) from being optimal for methanogenic conditions (6.5 to 8.5), resulting in an expected decrease in methane productivity, which fell from 5.79 to $1.61 \mathrm{~mol} \mathrm{CH}_{4} \cdot \mathrm{VSS}^{-1} \cdot \mathrm{day}^{-1} \times 10^{-5}$ (Table 2).

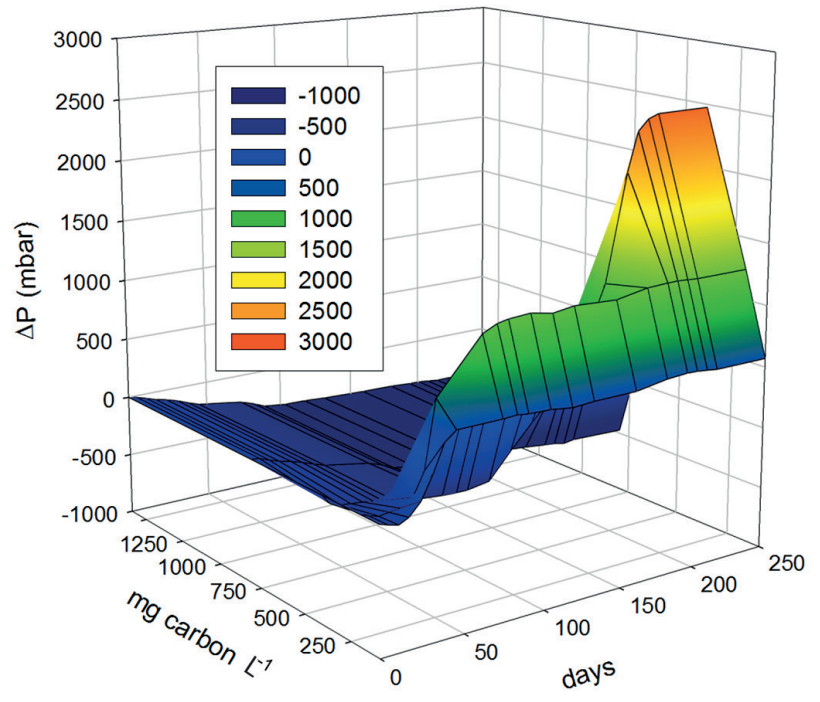

Figure 2

Biogas production and inhibition by caffeic acid. The lines represent the lag, exponential and plateau phases of the cumulative biogas produced at $100,200,400,800$ and $1600 \mathrm{mg} \cdot \mathrm{L}^{-1}$ carbon during 250 days.

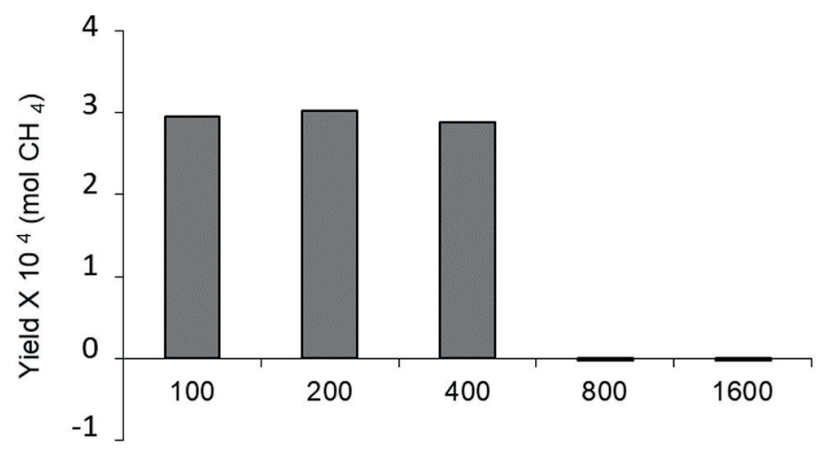

$\mathrm{C}\left(\mathrm{mg} \cdot \mathrm{L}^{-1}\right.$ Carbon)

Figure 3

Methane yield from experiments investigating the inhibition of biogas production. These amounts represent the total methane in both liquid and gas headspace reported in terms of carbon at the end of the experiment. The negative values are a clear indication of the inhibition of methane production from both caffeic acid and indigenous background biomass in the sludge. This negative effect may be due to simultaneous physicochemical and biochemical phenomena derived from the interaction of caffeic acid itself and with its surroundings. There was a standard deviation lower than 5\% for all plotted points.

\section{Lag phase and recalcitrance}

The method ISO 11734 (1999) is reliable for preventing falsepositive conclusions, but relies on using only one concentration of the target chemical in wastewater, overlooking the eventual inverse relationship between dose and response (inhibition or toxicity), i.e. hormesis. By using a range of concentrations, we found that negligible amounts of biogas at some concentrations and retention times were not proof of caffeic acid recalcitrance. For instance, at C400, inhibition was observed for 117 days before degradation and then biogas formation began. This indicates that anaerobes developed acclimation mechanisms to deal with such a concentration in a longer residence time. 
Therefore, we recommend that current methods should consider, for a proper acclimation, a range of concentrations and longer retention times when testing the anaerobic degradation of compounds, including those previously thought to be recalcitrant. It is probable that the lack of implementation of our recommendation would lead to caffeic acid being considered as not capable of being converted into methane by Borja et al. (1996). Our evaluation agrees with Moreno and Buitron (2004), who found that the use of different acclimation strategies and inocula affected the anaerobic digestion of 4-chlorophenol.

\section{Mechanism of caffeic acid anaerobic digestion}

Biogas production (methane and carbon dioxide) was achieved via the following proposed stoichiometric steps:

$$
\begin{gathered}
\mathrm{C}_{9} \mathrm{HO}_{4}+5 \mathrm{H}_{2} \mathrm{O} \rightarrow 4.5 \mathrm{CH}_{3} \mathrm{COOH} \\
4.5 \mathrm{CH}_{3} \mathrm{COOH} \rightarrow 4.5 \mathrm{CH}_{4}+4.5 \mathrm{CO}_{2} \\
\mathrm{C}_{9} \mathrm{H}_{8} \mathrm{O}_{4}+5 \mathrm{H}_{2} \mathrm{O} \rightarrow 4.5 \mathrm{CH}_{4}+4.5 \mathrm{CO}_{2}
\end{gathered}
$$

Caffeic acid is metabolized into a series of intermediates that lead to the production of acetic acid, which is utilised by methanogens to produce biogas. In order to identify some detectable biodegradation products, we considered the following aspects: (i) caffeic acid could lead to the formation of 4 out of 33 phenolics following the benzoyl-CoA pathway (Heider and Fuchs, 1997a, Schink et al., 2000, Boll et al., 2002); (ii) thermodynamically, the number of possibilities could be narrowed to 3 potential phenolics since caffeic acid can spontaneously be transformed to catechol, protocatechuic acid and 4HBA. HPLC analysis revealed that the double bond of caffeic acid was biological, reduced at 800 and 1600 into $4 \mathrm{HBA}$ and protocatechuic acid (Fig. 4). This was not observed in the controls (medium and CAF). In an interplay with sludge components, anaerobes converting caffeic acid into $4 \mathrm{HBA}\left(92 \mathrm{mg} \cdot \mathrm{L}^{-1}\right)$ performed better than those producing protocatechuic acid $\left(15 \mathrm{mg} \cdot \mathrm{L}^{-1}\right)$. Nevertheless, at higher concentrations, protocatechuic acid formers performed better (165 mg. $\mathrm{L}^{-1}$ ) (Fig. $4 \mathrm{~B}$ ). Therefore, the group of microorganisms able to carry out $\beta$-oxidation and reductive dehydroxylation was less sensitive than acetogens, which were unable to break the aromatic ring to produce acetate needed by methanogens to produce methane (Fig. 4 C). These in turn serve as sinks to dispose of extra electron equivalents in the trophic chain, e.g., using $\mathrm{H}_{2}$ to reduce $\mathrm{CO}_{2}$ into $\mathrm{CH}_{4}$ (Heider and Fuchs, 1997b). A thorough identification of metabolites by more advanced techniques could be more revealing, but this was beyond the scope of the current study.

\section{Fate of caffeic acid other than biogas and carbonates}

Caffeic acid was not completely mineralized to $\mathrm{CH}_{4}, \mathrm{CO}_{2}$ and carbonates, and the missing fraction was not detected (HPLC) in the liquid from $\mathrm{C} 100$ to $\mathrm{C} 400$. Losses also occurred at higher concentrations (C800 and C1600). This might be due to several biological, chemical and physical interactions. For instance, carbon might be used for cell mass construction (5 to 10\%) rather than biogas production (Healy and Young, 1979). This has also occurred in previous research on the fermentation of caffeic acid and other $\mathrm{C} 3$-aliphatic side chain products by Acetobacterium woodii and Peptostreptococcus productus, where

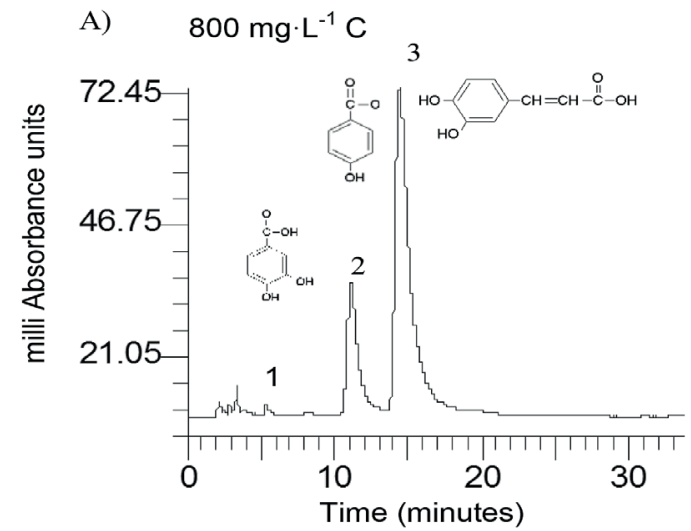

B)

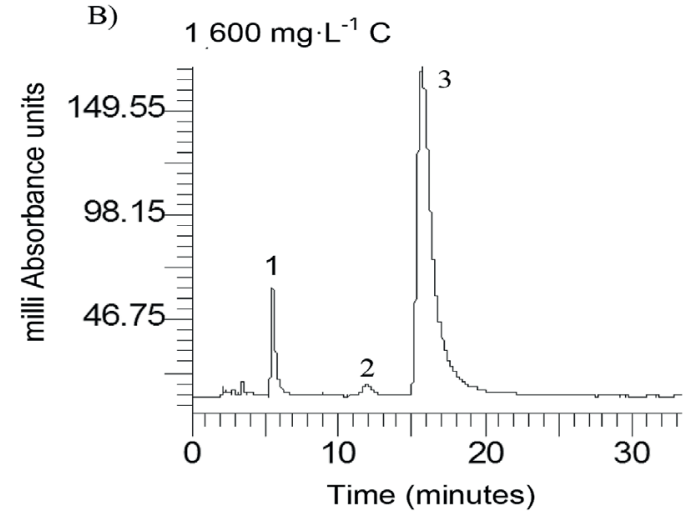

C)

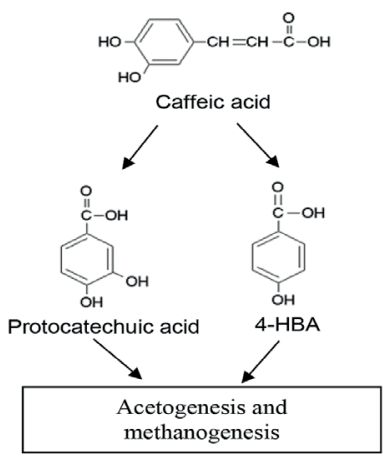

Figure 4

Metabolic products of the anaerobic degradation of caffeic acid. Liquid chromatography peaks (HPLC, $\lambda=254 \mathrm{~nm}$ ) are identified as follows: ( 1) Protocatechuic acid, (2) 4-hydroxybenzoic acid and (3) caffeic acid. $A$ and $B$ represent the peaks found at 800 and $1600 \mathrm{mg} \cdot L^{-1} C$. C represents the 9 -oxidation and reductive dehydroxylation of caffeic acid. The possibilities were narrowed from 33 potential phenols to 3 with only 2 reported here (4HBA and protocatechuic)

an increment in cell yield was accompanied with a lower acetate yield (Ljungdahl, 1986; Heider and Fuchs, 1997b). Lastly, caffeic acid might be adsorbed by the humic substances present in the sludge (Rochelle, 2001), or extracellular polymeric substances (Flemming and Wingender, 2001) or undergo autoxidation (Field and Lettinga, 1989).

Autoxidation of caffeic acid was observed in the negative blanks (caffeic acid and water) after 3 and 4 days for the incubate replicates at $35 \pm 1^{\circ} \mathrm{C}$ and $4 \pm 1^{\circ} \mathrm{C}$, respectively. This was evidenced by the formation of precipitated aggregates as well as a visual change in coloration from transparent to brown. This was not observed by Field and Lettinga (1989) due 
to the short period of their assay ( 1 to $15 \mathrm{~min}$ ). Autoxidation is not responsible for big losses of caffeic acid in the ultimate anaerobic biodegradability experiment, where black aggregates were observed in the controls (medium and caffeic acid), and were easily dissolved by hand shaking. A carbon balance from this system was carried out, revealing that $2 \mathrm{mg}$ of caffeic acid were transformed into unidentified materials.

\section{Intramolecular processes triggered by CAF}

CAF, like other phenolics, is a precursor of humic acids, which in turn are responsible for soil formation thanks to their capacity to stick together and form aggregates with themselves and some surrounding materials. In the experiments reported here, adsorption on the sludge matrix took place to a greater extent than expected. This was observed in the unfiltered samples stored at $4^{\circ} \mathrm{C}$ (Fig. 5), where caffeic acid was adsorbed on the sludge matrix at a ratio of $1.1 \mathrm{mg} \cdot \mathrm{L}^{-1} \cdot \mathrm{day}^{-1}$. No significant changes were observed in the frozen samples.
This suggests that the adsorption process should be avoided when storing samples, for instance, by filtering the liquid fraction from the sludge matrix before storage at $4^{\circ} \mathrm{C}$ or by freezing the samples. We thus suggest that this recommendation is included in the standard APHA method for the analysis of phenols (APHA, 1998). Nevertheless, the use of freezing must be studied in more detail. Adsorption was also inferred at C800 and $\mathrm{C} 1600$ as $53.3 \%$ and $28.6 \%$ of caffeic acid were lost as confirmed by HPLC. It is likely that a fraction of caffeic acid was autoxidised to form humic substances (Field and Lettinga, 1989) and transformed to undetectable intermediates or assimilated during cell growth (Healy and Young, 1979).

\section{Kinetics and thermodynamic aspects}

Thermodynamically, under the hypothetical conditions set herein and without the presence of a biocatalyst, caffeic acid should have the natural tendency to produce methane (see stoichiometric Eq. 3 and Table 3) and thus lead to a more
A)

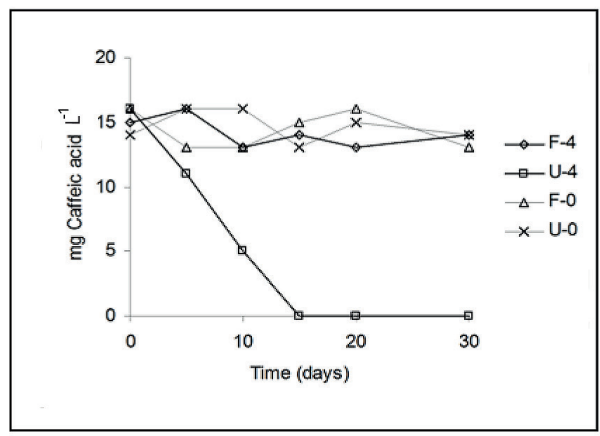

C)

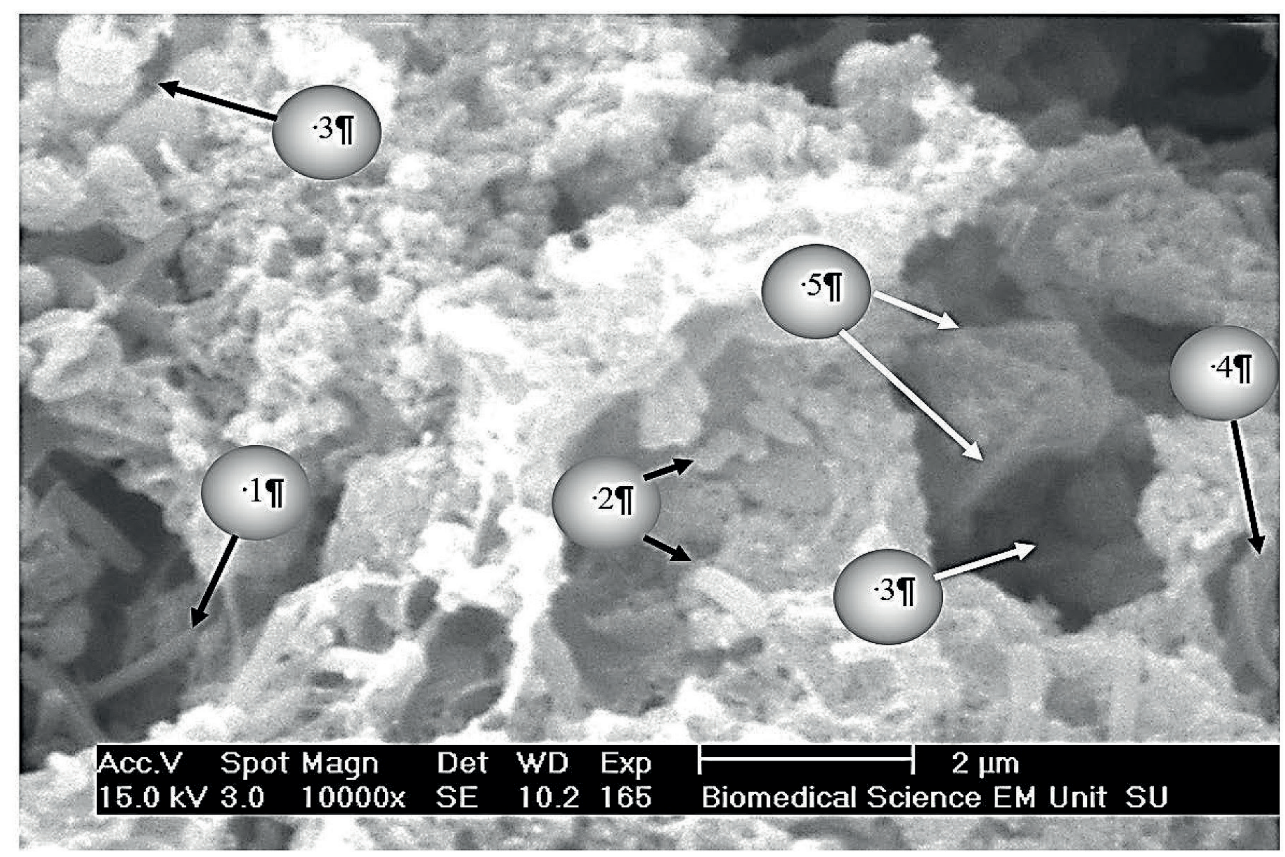

B)

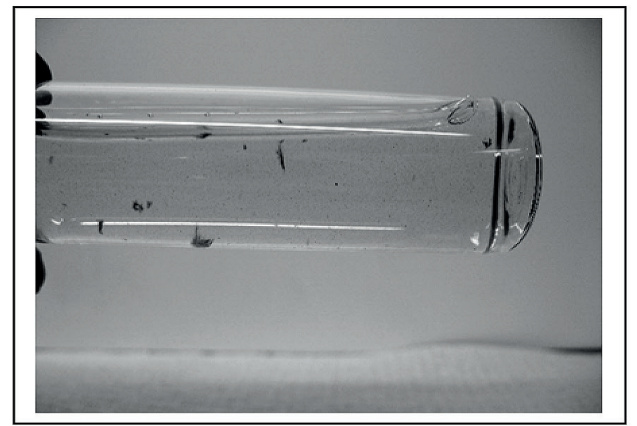

\section{Figure 5}

Adsorption of caffeic acid on sludge. A) quantified caffeic acid in filtered (F-0,4) and unfiltered (U-0,4) samples at 4 and $0^{\circ} \mathrm{C}$. B) caffeic acid aggregate due to autoxidation. C) SEM of methanogenic sludge degrading caffeic acid. Rod-shaped anaerobes: (1) Filamentous microorganisms resembling Methanospirillum sp. (2) Short and long-shaped anaerobes Syntrophobacter wolinii. (3) Cluster of anaerobes similar to Methanosarcina sp. (4) Comma-shaped microorganisms resembling Desulphovibrio sp. (5) Filamentous bacilli 
TABLE 3

Thermochemical data of caffeic acid standard formation ( $f$ ) and biomethanation ( $r$ )

\begin{tabular}{|l|c|l|}
\hline & $\mathrm{KJ} \cdot \mathrm{moL}^{-1}$ & \multicolumn{1}{c|}{ Notes } \\
\hline$\Delta \mathrm{G}_{\mathrm{f}}^{0}$ & -357.45 & calculated using only one method (Joback and Reid, 1987) \\
\hline$\Delta \mathrm{H}_{\mathrm{f}}^{0}$ & $-384.93 \pm 15$ & calculated 3 different methods (Zavitsas et al., 2010) \\
\hline$\Delta \mathrm{S}_{\mathrm{f}}^{0}$ & $-0.092 \mathrm{~kJ} \cdot \mathrm{moL}^{-1} \cdot \mathrm{K}^{-1}$ & Calculated here \\
\hline$\Delta \mathrm{H}_{\mathrm{r}}^{0}$ & -293.68 & Calculated here \\
\hline$\Delta \mathrm{G}_{\mathrm{r}}^{0}$ & -459.96 & Calculated here \\
\hline $\mathrm{K}$ & $4.047 \times 10^{80}$ & Dimensionless. Calculated here. \\
\hline$\Delta \mathrm{S}_{\mathrm{r}}^{0}$ & 0.558 & Calculated here \\
\hline
\end{tabular}

The stoichiometric methanation reaction was calculated by using Symons and Buswell equation (1933). The values reported here were calculated from data at standard conditions $(101.3 \mathrm{KPa})$ and $298 \mathrm{Kelvin}$, available at the National Institute of Standards and Technology web site, accessed on 1 June 2015. Calculations were performed as follows: $\Delta \mathrm{G}_{\mathrm{f}}^{0}$, by the Joback method; $\Delta \mathrm{H}_{\mathrm{f}}^{0}$, by Andreas method (2010); $\Delta \mathrm{S}_{\mathrm{f}}^{0}$, with this equation $\Delta \mathrm{S}_{\mathrm{f}}^{0}=\left(\Delta \mathrm{H}_{\mathrm{r}}^{0}-\Delta \mathrm{G}_{\mathrm{f}}^{0}\right) / 298 ; \Delta \mathrm{H}_{\mathrm{r}}^{0}$ with this equation $\Delta \mathrm{H}_{\mathrm{r}}^{0}=\sum_{\mathrm{i}}^{\text {Products }} \mathrm{n}_{\mathrm{i}} \cdot \Delta \mathrm{H}_{\mathrm{f}, \mathrm{i}}^{0}-\sum_{\mathrm{j}}^{\text {Reactants }} \mathrm{n}_{\mathrm{i}} \cdot \Delta \mathrm{H}_{\mathrm{f}, \mathrm{j}}^{0} ; \Delta \mathrm{G}_{\mathrm{r}}^{0}$ with this equation $\Delta \mathrm{G}_{\mathrm{r}}^{0}=\sum_{\mathrm{i}}^{\text {Products }} \mathrm{n}_{\mathrm{i}} \cdot \Delta \mu_{\mathrm{f}, \mathrm{j}}^{0} ; \Delta \mathrm{S}_{\mathrm{r}}^{0}$ with this equation $\Delta \mathrm{S}_{\mathrm{r}}^{0}=\left(\Delta \mathrm{H}_{\mathrm{r}}^{0}-\Delta \mathrm{G}_{\mathrm{r}}^{0}\right) / 298$ and $K$ by applying this equation $K=\exp \left(-\Delta \mathrm{G}_{\mathrm{r}}^{0}(\mathrm{R} \cdot \mathrm{T})\right.$.

randomized state $\left(+\Delta S_{r}^{0}\right)$. We found that if methanation occurs, then the extent of methanation $(\xi)$ is higher than that of phenol and $4 \mathrm{HBA}$, i.e. $\xi$ comparatively closer to $100 \%$, probably because its thermodynamic equilibrium constant $(\mathrm{K})$ was 50 orders of magnitude higher than those of phenol and 4HBA.

Our calculations show that the entropy created by the formation of solid caffeic acid is negative although very small in absolute value (Fig. 6), indicating that the creation of a more ordered state (solid CAF) cannot be reached spontaneously and thus an energy input is needed. Again, this is valid under the hypothetical conditions set herein and using thermodynamic equations originally made for non-catalysed ideal systems under standard conditions. However, gathering such a small amount of energy from the digesting sludge, for solid caffeic acid formation, would not be difficult due to the experimental conditions involved in the present experiment: highly reducing (added sulphide nonahydrate); biocatalysed, non-ideal and non-standard. Moreover, cells were certainly working at a steady state and far-from-equilibrium to remain alive. In fact, we observed the aggregation of caffeic acid particles in systems with and without sludge. It can be suggested that certain concentrations of caffeic acid are likely to lead to solid caffeic acid formation even though the likelihood of caffeic acid producing methane remains relatively higher (Fig. 6).

The thermodynamics of solid caffeic acid formation and methanation can explain the spontaneity, degree of disorder and probability of both reactions occurring. It is accepted that any system tends to approach the condition of minimum total free energy to reach chemical equilibrium. However, thermodynamics does not explain how fast (kinetics) such a transformation will occur, nor if the reacting species will reach another metastable configuration. The direction for each process is likely to be affected by the complexity of the digesting sludge in the bioreactors.

The bioreactors used in this work contained a diversity of catalysts, e.g. cells, EPS and sludge-born minerals. At low caffeic acid concentrations, biogas formation occurred faster and as caffeic acid concentrations kept increasing, the biocatalytic activity reduced until it became negligible in both toxicity and biodegradability tests, implying the absence of mineral catalysis mediating biogas formation. Thus, biological and mineral catalytic activity did not reduce the energetic barrier (activation energy) allowing for

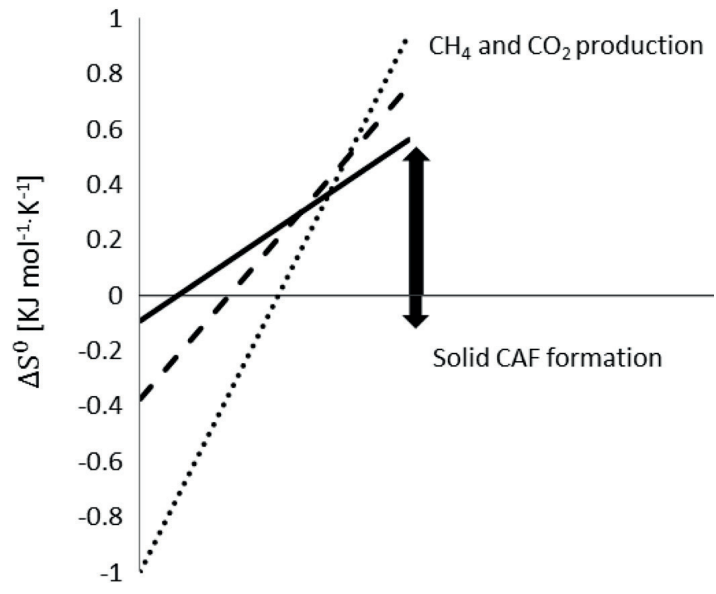

Figure 6

Entropy comparison of two reactions: biogas production and solid caffeic acid formation. This graphic shows the likelihood that a more disordered state will naturally occur. Solid line: CAF; dashed line: phenol and round dotted line: $4 H B A$. The horizontal axis does not represent any value but a mere division between the two main reactions when $\Delta S^{\circ}=0$.

methanogenesis to proceed, and thus aggregation proceeded independently (the likelihood of spontaneous methanation remains the same). A different thermodynamic analysis is needed to explain why caffeic acid aggregation occurred, and is discussed as follows.

Aggregation can be explained by analysing the randomness to create surfaces of CAF, which has poor solubility and affinity to be dispersed in water (lyophobic) and thus will easily precipitate. In order to expand the area of a caffeic acid particle, by making it smaller, work must be done (an undesired action in the pursuit of low-carbon wastewater treatment technologies). This action would lead to a more disordered state $(+\Delta S)$ in caffeic acid particles, lowering the Helmholtz free energy and thus naturally causing flocculation, which results in a smaller total surface area exposed by all caffeic acid particles $(\mathrm{d} \sigma<0)$. To aggregate, caffeic acid particles would need to transfer energy as work to form bigger aggregates $(\mathrm{dG}<0)$. In our experiments, caffeic acid aggregation would have been enhanced by: autoxidation, self-aggregation and 
chelation to other materials in the sludge. The formation of aggregates observed indicates that the conditions prevailing in this system impose thermodynamics favouring colloid destabilization and thus aggregation - with itself and other molecules around it. Caffeic acid would not form a colloid and thus agglomerate in particles since it remains kinetically variable and thermodynamically unstable $(+\Delta S)$. This suggests two practical mechanisms for destabilizing the lyophobic caffeic acid molecule: firstly, that there is an attraction between electrical double layers of growing caffeic acid particles and, secondly, that there is a strong stericity of entropic destabilization (cost in energy due to overlapping electron clouds), i.e., steric hindrance, as was found after analysing the distribution of caffeic acid electrons in its planar geometry by using results from two structural studies (Kumar et al., 2015, VanBesien and Marques, 2003).

When compared to other phenolics, the standard free energy of formation $\left(\Delta G_{f}^{o}\right)$ of solid caffeic acid is similar to that of $4 \mathrm{HBA}$, which is also known to form aggregates under the same conditions reported herein. However, the $-\Delta G_{f}^{0}$ of caffeic acid and 4HBA are nearly 8 -fold smaller than the free energy of formation of liquid phenol, which does not flocculate in similar conditions because it lacks the electronic capacity to become sticky that caffeic acid and 4HBA have. Caffeic acid is a highly efficient hydrogen donor that allows intermolecular hydrogen bonding (Kumar et al., 2015) and thus should lead to dimerization.

\section{SEM analysis}

Extracellular polymeric-like substances in sludge, e.g., polysaccharides, proteins, phospholipids and humic substances, allow the retention of exoenzymes and therefore establish functionality of a multicellular synergistic microconsortia (Flemming and Wingender, 2001). In this work, SEM analysis confirmed that the EPS structure remained practically unchanged regardless of the increase in concentration of caffeic acid (Fig. 5 C). It was found that different sludge samples contained similarshaped microorganisms, e.g., filamentous, bacillus, cocci quartets and comma-shaped. Acidogenic, acetogenic and methanogenic anaerobes are likely to be in this aggregate. For instance, the widespread strictly-anaerobic rod-shaped Clostridium sp., responsible for converting metabolites into acids, has been found in several anaerobic digesters. Since caffeic acid most probably followed the acetyl coenzyme-A pathway (Boll et al., 2002, Schink et al., 2000), its conversion from acetate to methane was likely done by specialised organisms, for instance Methanosarcina sp. (large archaea cocci quartet) and Methanosaeta sp. (square-ended rods filaments), which are the only known acetate-metabolizing methanogens (Speece, 1983). The identity and function (ecophysiology) of such microbes is beyond the scope of this study but could be revealed by applying environmental molecular microbiology approaches.

\section{CONCLUSIONS}

Anaerobic digestion (AD) seems to be a sustainable treatment for wastes containing caffeic acid and, to be deployed, more needs to be known about the toxicity, inhibition and biodegradability of caffeic acid, using standardized methods. The toxicity assessment showed that $80 \%$ of biogas production from readily digestible biomass was inhibited at
389 mg CAF.g ${ }^{-1}$ VSS. The assessment of ultimate anaerobic biodegradability showed that up to $52 \%$ of caffeic acid was ultimately biodegraded. $\beta$-oxidation and reductive dehydroxylation are likely to be initial activation reactions to form protocatechuic acid and 4HBA. Adsorption of caffeic acid (53.3\% and $28.6 \%)$ to the sludge occurred at inhibitory concentrations. Caffeic acid aggregation would have been enhanced by: autoxidation, self-aggregation and chelation to other materials in the sludge. Under the conditions presented herein, caffeic acid tends to aggregate and would not form a stable mixture since it remains kinetically variable and thermodynamically unstable. The EPS structure remained unchanged regardless of the increase in concentration of caffeic acid. Reasonable concentrations of caffeic acid could be co-digested with a similar readily digestible biomass with an expected reduction in biogas production. It is thus feasible to treat caffeic acid wastes by anaerobic digestion and adsorption of its derivates or both.

\section{ACKNOWLEDGEMENTS}

We would like to thank CONACyT (grant 167740 www. ernestohernandez.org) for their sponsorship and for making publication of the present work possible. Thanks also go to Andreas Zavitsas for providing three different calculations of standard heat of formation. We would like to thank NB Coutelle for providing help with language use, proofreading the article and providing editing assistance.

\section{REFERENCES}

APHA (1998) Standard Methods for the Examination of Water and Wastewater. American Public Health Association, Washington.

BATSTONE DJ, KELLER J, ANGELIDAKI I, KALYUZHNYI SV, PAVLOSTATHIS SG, ROZZI A, SANDERS WTM, SIEGRIST H and VAVILIN VA (2002) The IWA Anaerobic Digestion Model No 1 (ADM1). Water Sci. Technol. 45 65-73.

BECCARI M, BONEMAZZI F, MAJONE M and RICCARDI C (1996) Interaction between acidogenesis and methanogenesis in the anaerobic treatment of olive oil mill effluents. Water Res. 30 183-189. https://doi.org/10.1016/0043-1354(95)00086-Z

BO Z, SHUAI XR, MAO S, YANG HC, QIAN JJ, CHEN JH, YAN JH and CEN K (2014) Green preparation of reduced graphene oxide for sensing and energy storage applications. Sci. Reports 44684 , $8 \mathrm{p}$.

BOLL M, FUCHS G and HEIDER J (2002) Anaerobic oxidation of aromatic compounds and hydrocarbons. Curr. Opin. Chem. Biol. 6 604-611. https://doi.org/10.1016/S1367-5931(02)00375-7

BORJA R, BANKS CJ, MAESTRO-DURAN R and ALBA J (1996) The effects of the most important phenolic constituents of olive mill wastewater on batch anaerobic methanogenesis. Environ. Technol. 17 167-174. https://doi.org/10.1080/09593331708616373

CRAIOVEANU MG, GHEORGHE S, LUCACIU I, STOICA L and CONSTANTIN C (2014) Assessment of aquatic toxicity of the caffeic acid complexed with $\mathrm{Cr}$ (III) and $\mathrm{Pb}$ (II) in the flotation process. Revista Chim. 65 339-343.

D'ANNIBALE A, STAZI SR, VINCIGUERRA V and SERMANNI G (2000) Oxirane-immobilized Lentinula edodes laccase: stability and phenolics removal efficiency in olive mill wastewater. J. Biotechnol. 77 265-273. https://doi.org/10.1016/ S0168-1656(99)00224-2

EVANS WC and FUCHS G (1988) Anaerobic degradation of aromatic compounds. Annu. Rev. Microbiol. 42 289-317. https://doi. org/10.1146/annurev.mi.42.100188.001445

FEDORAK PM and HRUDEY SE (1984) The effects of phenol and some alkyl phenolics on batch anaerobic methanogenesis. Water Res. 18 361-367. https://doi.org/10.1016/0043-1354(84)90113-1

FIELD JA and LETTINGA G (1989) The effect of oxidative coloration on the methanogenic toxicity and anaerobic 
biodegradability of phenols. Biol. Wastes 29 161-179. https://doi. org/10.1016/0269-7483(89)90128-6

FIESTAS-ROS-DE-URSINOS JA and BORJA-PADILLA R (1996) Biomethanization. Int. Biodeterior. Biodegrad. 38 145-153. https:// doi.org/10.1016/S0964-8305(96)00043-1

FLEMMING HC and WINGENDER J (2001) Relevance of microbial extracellular polymeric substances (EPSs) - Part II: Technical aspects. Water Sci. Technol. 43 9-16.

HEALY JBJ and YOUNG LY (1979) Anaerobic biodegradation of eleven aromatic compounds to methane. Appl. Environ. Microbiol. 38 84-89.

HEIDER J and FUCHS G (1997a) Anaerobic metabolism of aromatic compounds. Eur. J. Biochem. 243 577-596. https://doi. org/10.1111/j.1432-1033.1997.00577.x

HEIDER J and FUCHS G (1997b) Microbial anaerobic aromatic metabolism. Anaerobe 3 1-22. https://doi.org/10.1006/ anae.1997.0073

HERNANDEZ E (2007) Anaerobic biofermentation of phenol. PhD, The University of Sheffield.

ISO (2003) Water quality. Determination of inhibition of gas production of anaerobic bacteria. Part 1: General test. first ed.: CEN. ISO, Brussels.

ISO (1999) Water quality. Evaluation of the "ultimate" anaerobic biodegradability of organic compounds in digested sludge. Method by measurement of the biogas production. ISO, Brussels.

KUMAR N, PRUTHI V and GOEL N (2015) Structural, thermal and quantum chemical studies of p-coumaric and caffeic acids. J. Mol. Struct. 1085 242-248. https://doi.org/10.1016/j. molstruc.2014.12.064

LJUNGDAHL LG (1986) The autotrophic pathway of acetate synthesis in acetogenic bacteria. Annu. Rev. Microbiol. 40 415-450. https:// doi.org/10.1146/annurev.mi.40.100186.002215

MICHAILOF C, MANESIOTIS P and PANAYIOTOU C (2008) Synthesis of caffeic acid and p-hydroxybenzoic acid molecularly imprinted polymers and their application for the selective extraction of polyphenols from olive mill waste waters. J. Chromatogr. A 1182 25-33. https://doi.org/10.1016/j. chroma.2008.01.001

MORENO G and BUITRON G (2004) Influence of the origin of the inoculum and the acclimation strategy on the degradation of 4-chlorophenol. Bioresour. Technol. 94 215-218. https://doi. org/10.1016/j.biortech.2003.12.011

OLTHOF MR, HOLLMAN PCH, BUIJSMAN MNCP, VAN AMELSVOORT JMM and KATAN MB (2003) Chlorogenic acid, quercetin-3-rutinoside and black tea phenols are extensively metabolized in humans. J. Nutr. 133 1806-1814.

ROCHELLE PA (ed.) (2001) Environmental Molecular Microbiology: Protocols and Applications. Horizon Scientific Press, Norfolk.

SCHINK B, PHILIPP B and MÜLLER J (2000) Anaerobic degradation of phenolic compounds. Naturwissenschaften 87 12-23. https:// doi.org/10.1007/s001140050002

SIERRA-ALVAREZ R and LETTINGA G (1991) The effect of aromatic structure on the inhibition of acetoclastic methanogenesis in granular sludge. Appl. Microbiol. Biotechnol. 34 544-550. https:// doi.org/10.1007/BF00180586

SIKKEMA J, DE-BONT JAM and POOLMAN B (1995) Mechanisms of membrane toxicity of hydrocarbons. Microbiol. Rev. 59 201-222.

SORLINI CAV, FERRARI A and RANALLI G (1986) The influence of some phenolic acids present in oil-mill waters on microbicgroups for methanogenesis. International Symposium Olive By-products Valorization, 1986, Seville. FAO, United Nations Development Programme. 81-88.

SPEECE RE (1983) Anaerobic biotechnology for industrial wastewater treatment. Environ. Sci. Technol. 17 416-427. https://doi. org/10.1021/es00115a725

STOJKOVIĆ D, PETROVIĆ J, SOKOVIĆ M, GLAMOČLIJA J, KUKIĆ-MARKOVIĆ J and PETROVIĆ S (2013) In situ antioxidant and antimicrobial activities of naturally occurring caffeic acid, p-coumaric acid and rutin, using food systems. J. Sci. Food Agric. 93 3205-3208. https://doi.org/10.1002/jsfa.6156

VANBESIEN E and MARQUES MPM (2003) Ab initio conformational study of caffeic acid. J. Mol. Structure-Theochem 625 265-275. https://doi.org/10.1016/S0166-1280(03)00026-5

ZHAVEH S, MOHSENIFAR A, BEIKI M, KHALILI ST, ABDOLLAHI A, RAHMANI-CHERATI T and TABATABAEI M (2015) Encapsulation of Cuminum cyminum essential oils in chitosancaffeic acid nanogel with enhanced antimicrobial activity against Aspergillus flavus. Ind. Crops Prod. 69 251-256. https://doi. $\operatorname{org} / 10.1016 /$ j.indcrop.2015.02.028 